\title{
Uma história de partidas: mulheres, emigrantes e estrangeiros
}

\author{
Mônica Figueiredo \\ (Universidade Federal do Rio de Janeiro / \\ Pesquisadora da Biblioteca Nacional)
}

JORGE, Silvio Renato. Sobre mulheres e estrangeiros: alguns romances de Olga

Gonçalves. Niterói: EdUFF, 2009.

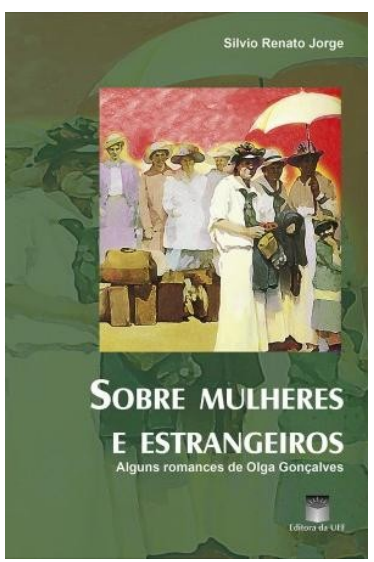

Silvio Renato Jorge é professor de Literatura Portuguesa na Universidade Federal Fluminense e tem pelos romances de Olga Gonçalves um apreço especial. A obra da autora, não de hoje, é objeto privilegiado de reflexão em seus ensaios críticos e assunto constante nos cursos ministrados na Graduação e na Pós-Graduação do Instituto de Letras da UFF. Para além de outras qualidades, o livro acerta na escolha de Olga Gonçalves, rompendo assim com o silêncio sobre uma obra romanesca "iniciada em 1975, com a publicação de A floresta em Bremerhaven, e interrompida em 1991, com o livro Eis uma história" (p. 11). Olga Gonçalves falece em 2004, encerrando uma carreira que reúne tradução, poesia e, sobretudo romance, forma que a fez uma escritora premiada (Prêmio Ricardo Malheiros, recebido em 1975, pela $A$ floresta em Bremerbaven), e que se concretizou em quase uma dezena de narrativas marcadas por uma "reflexão crítica bastante consistente acerca dos problemas que envolvem a sociedade portuguesa no período pós-revolucionário" (p. 11).

Silvio Renato Jorge propõe uma leitura crítica da obra da autora de Ora Esguardae (1982), partindo da análise de três outros romances: A floresta em Bremerhaven, Este verão o emigrante là-bas (1978), e Rudolfo (1985). Não se pode esquecer que em comum temos três narrativas que partem da criação de tramas cujos protagonistas são os pequenos heróis, aqueles anônimos que têm suas vidas marcadas pela necessidade de partida, sejam eles emigrantes recémchegados ao Portugal de Abril, sejam emigrantes desenraizados numa França 
para sempre estranha, ou simplesmente "retornados", filhos da ressaca histórica de um Portugal imperialista. Com razão, o A. define a intenção do texto ficcional de Olga Gonçalves como sendo a de "problematizar essas totalidades através da exposição de suas contradições internas" (p. 11).

Não se pode perder de vista que o caráter de questionamento crítico se efetiva nos romances de Olga Gonçalves através da presença de grupos marginalizados que expõem outra face da identidade portuguesa. A escrita é aqui "elaborada na margem: a margem do texto, a margem da língua, a margem da história" (p. 12). O discurso ficcional aposta na descontinuidade narrativa, na importância do diálogo intertextual e no jogo ficcional, pois igualmente crê que é do descontínuo, da lacuna e da ruína que a história dos homens comuns (re)nasce. Assim, Sobre mulheres e estrangeiros: alguns romances de Olga Gonçalves deseja apreender "os instrumentos utilizados pela autora para, através da problematização da escrita, romper com os parâmetros da narrativa tradicional e, sobretudo, rever os conceitos que envolvem as relações entre a literatura, história e memória" (p. 12).

Silvio Renato Jorge, apostando no dialogismo que aprendeu com Mikhail Bakhtin, fará com que seu texto "fale" com o de Olga Gonçalves, usando como intermediadoras as vozes teóricas de Eduardo Lourenço, Boaventura de Souza Santos, Edward Said, Stuart Hall Linda Hutcheon, Julia Kristeva, Patrícia Waugh, Roland Barthes, Walter Benjamin e Umberto Eco, para só citar alguns exemplos. Ao defender que é o plurilinguismo o "elemento organizador do romance [de Olga Gonçalves,]" (p. 14), o A. acaba por também definir a forma como seu discurso teórico irá dialogar não só com a ficção, mas também com todo o arcabouço teórico do qual se vale.

Ao reconhecer na obra da autora de $A$ floresta em Bremerhaven a "influência da intertextualidade e da auto-referencialidade no processo de desestruturação e descentralização da escrita ficcional" (p. 14), o crítico acaba por provar que só uma escrita que não teme a margem pode ser capaz de apreender as imagens - invariavelmente tratadas como marginais -, da mulher e do estrangeiro, ex-cêntricos caros à narrativa pós-moderna e à vertente da metaficção historiográfica.

$\mathrm{Na}$ tentativa de compreender os descaminhos vividos pela identidade portuguesa, Sílvio Renato Jorge repassa alguns dos textos fundadores da literatura nacional - Os Lusiadas, Viagens na minha terra, "O sentimento dum ocidental", Mensagem e Gaibéus, privilegiadamente -, pois não duvida que "a identidade cultural é um compósito, em que se encaixam diversos elementos, contemporâneos ou não" (p. 19), ainda mais se lembrarmos que, no caso português, muitas foram as obras que traçaram "um caminho marcante da experiência colonial portuguesa, narrando a complexidade cultural da nação" (p. 20). Postos em diálogo, Fernão Lopes, Camões, Almeida Garrett, Cesário Verde, Fernando Pessoa e Alves Redol estão ali reunidos para afirmarem, ao lado de Edward Said, que as nações são mesmo narrativas.

Entendendo a "identidade cultural como um discurso de poder", Silvio Renato Jorge alerta que qualquer tentativa de reformulação da fisionomia identitária deve partir da problematização de "seu caráter centralizador e da preocupação com as referências hegemônicas" (p. 36). Apostando, com Boaventura de Souza Santos, nos conceitos de "semiperiferia" e de "cultura de fronteira", o A. propõe que (re)analisemos "as culturas das nações questionando as construções oficiais", na tentativa de perceber que "a soberania do Estado não possui uma correspondência no domínio cultural - o que vale dizer que nenhuma cultura é autocontida, nem, por outro lado, indiscriminadamente aberta" (p. 37). 
Deste modo, ao recuperar os (des)caminhos percorridos pela emigração e ao perseguir as representações do feminino no romance de Olga Gonçalves, o que o crítico pretende é provar que a escrita ficcional cria um novo modo de "identificação do português" através da recriação de "um espaço plural, em que a diversidade cultural se mostra como opção válida ao se delinear um novo sentido para a idéia de lusitanidade"(p. 39).

Resgatando a imagem do estrangeiro e da mulher, a ficção de Olga Gonçalves "não os apresenta como modelos fixos e completos a partir dos quais se possa construir uma imagem acabada da existência portuguesa" (p. 40). Antes, é privilegiando as suas condições de "outro" que os romances da autora apostam na necessidade de se abrir espaço para que aqueles que estão deslocados possam pôr em dúvida o confortável lugar ocupado por todas as formas de centro. Como afirma Silvio Renato Jorge, é a partir do outro "que o centro delimita as suas margens; é a partir dele, muitas vezes também que estas margens questionam a existência do direito de qualquer tipo de centralidade" (p. 41).

Ao analisar A floresta em Bremerhaven, o A. procura mostrar a importância do trabalho como veículo organizador das vidas daqueles que tiveram os destinos cortados pela necessidade de emigrar. Manuel e sua esposa são estrangeiros na Alemanha, para eles "o trabalho se situa como uma terra eleita, pois se transforma em uma qualidade pessoal e intransferível" (p. 49), que é capaz de lhes repor a dignidade que a condição de ex-patriados pôde de perto ameaçar. Silvio Renato Jorge ainda desdobra a sua leitura ao refletir sobre a representação do feminino feita pela narrativa de Olga Gonçalves, desvelando a intenção da autora, que verdadeiramente pretende "implodir o cerceamento da palavra de que as mulheres são vítimas, através de uma elaboração textual que procurará estratégias de valorização do feminino" (p. 66).

Em Este verão o emigrante là-bas, os emigrantes são agora "personagens de uma antiepopéia do exílio", denúncia viva da "diáspora conduzida pela mão do sistema socioeconômico profundamente excludente em que (sobre)viviam" (p. 78). Flagrados numa França que não sabe acolher, os portugueses emigrados sofrem por não pertencerem a lugar nenhum e, talvez, seja no interior da língua que a sensação de (des)pertenciamento é vivida de forma mais contundente. Silvio Renato Jorge é sensível a este aspecto ao mostrar como a narrativa de Olga Gonçalves dá registro à dificuldade do emigrante em assimilar a nova língua, pois "ela permanece como algo artificial, como discurso secundário, utilizado para fraturar a fala materna e para povoar um mundo fantasmático marcado pela exclusão" (p. 81).

Por último resta $R u d o l f o$, narrativa que conta os percalços de um retornado angolano, que enfrenta uma Lisboa inóspita e indiferente, vivendo de pequenos furtos. Ao perseguir sua trajetória, o romance de Olga Gonçalves dá vida a um personagem que ocupa "duplamente a margem, visto como estrangeiro seja em Angola, seja em Portugal, [ele] vive uma situação pendular" (p. 109). Mais do que um personagem e a sua história, Rudolfo é um projeto de escrita, pois partindo de "um recorte temático em que o processo de descentramento vivido pelo retornado é evidenciado, ele acaba por propor também o próprio ato da escrita como objeto de reflexão, assumindo diante do processo de produção textual, uma atitude que delineia o romance como uma escrita elaborada a partir do questionamento do centro" (p. 116).

Sobre mulheres e estrangeiros é afinal um amoroso discurso crítico sobre o romance de Olga Gonçalves. Partindo de questionamentos que hoje afligem boa parte da intelectualidade ocidental, conceitos como "fronteira", "margem", 
"identidade", "condição feminina" e "experiência estrangeira" são postos a serviço de uma leitura inteligente, clara e bem articulada - não alheia às exigências de um elegante estilo -, que sabe que é "na mentira do encantamento da língua-mãe e em busca dos seus filhos dispersos pelo mundo", que o romance de Olga Gonçalves cria a sua verdade. É claro que se trata de uma "verdade relativa, construída aparentemente sobre a ruína de caminhos tortuosos. Verdade que talvez sequer pretenda ser verdade. Mas, sobretudo, verdade que se reconhece fingida a partir da escrita, da busca de transformar a palavra em arte" (p. 131). 